\title{
An Empirical Test of IS Leadership as the Driving Force in Improving IS Performance: The Service Level Perspective
}

\author{
Zhengzhong Shi \\ Charlton College of Business Administration, \\ University of Massachusetts at Dartmouth, \\ North Dartmouth, MA, USA
}

\section{zshi@umassd.edu}

\begin{abstract}
Existing information system (IS) studies have conceptualized various IS competences and investigated empirically how these competences can impact IS performance. However, these studies incorporate only a few IS competences and the relationships among them are not taken into consideration. This paper is intended to fill these gaps. A more comprehensive set of IS competences is incorporated and the service level perspective of the Strategic Alignment Model is applied to establish the theoretical foundation. An empirical test of the model is conducted. The results show that IS leadership positively impacts IS performance by driving other IS competences. These results partially validate the service level perspective of the alignment model. The model development and test also demonstrate that we need to consider all the information, IT, and organization challenges when dealing with IS management issues. Implications of this research for future studies and practice are presented at the end.
\end{abstract}

Keywords: Strategic alignment model, the service level perspective, IS competence, IS performance, empirical test

\section{Introduction}

Existing IS studies have investigated various IS competences and explored how these competences can impact IS performance (e.g., C. P. Armstrong \& Sambamurthy, 1999; Bassellier \& Benbasat, 2004; Bharadwaj, 2000; Boynton, Zmud, and Jacobs, 1994; Broadbent, Weil, \& St. Clair, 1999; Feeny \& Willcocks, 1998; Lee, Trauth, \& Farwell , 1995; Nelson \& Cooprider, 1996; ; Ray, Muhanna, \& Barney, 2005; Santhanam \& Hartono, 2003; Venkatraman, 1994). For example, Armstrong \& Sambamurthy (1999) investigated how the business/IS knowledge and the knowing system of senior IS executives can impact IT assimilation. Broadbent, Weil, and St.

Material published as part of this publication, either on-line or in print, is copyrighted by the Informing Science Institute. Permission to make digital or paper copy of part or all of these works for personal or classroom use is granted without fee provided that the copies are not made or distributed for profit or commercial advantage AND that copies 1) bear this notice in full and 2) give the full citation on the first page. It is permissible to abstract these works so long as credit is given. To copy in all other cases or to republish or to post on a server or to redistribute to lists requires specific permission and payment of a fee. Contact Publisher@InformingScience.org to request redistribution permission.
Clair (1999) examined how IS infrastructure can facilitate business process reengineering to improve organizational performance. Ray, Muhanna, and Beney (2005) found that tacit, socially complex, and firm specific IS resources, such as IS relationships with user managers, explain the variations in customer service process performance across firms. These studies are certainly helpful in guiding business/IS managers when 
they are designing and implementing business and IS strategies. However, this research stream is lacking (1) the integration of a more comprehensive set of IS competences, and (2) the incorporation of how the relationships among these competences may improve IS performance.

This study is intended to fill these gaps. First, a more comprehensive set of IS competences, including IS leadership, business system thinking, relationship building, architecture planning, and making technology work, is incorporated into the conceptual model. Second, the service level perspective of the Strategic Alignment Model is applied to establish the theoretical linkages among IS competences, and these linkages are taken into consideration in an empirical test. Third, the test results demonstrate that IS leadership positively impacts IS performance by driving other IS competences. And, as a conclusion, all the findings together help validate the service level perspective of the alignment model (Henderson \& Venkatraman, 1993). Fourth, the model development and test also demonstrate the need to consider information, IT, and organization challenges of an IS when studying IS management issues.

\section{Theoretical Foundation, Constructs, and Hypotheses}

\section{The Strategic Alignment Model and Its Service Level Perspective}

The Strategic Alignment Model is proposed by Henderson and Venkatraman (1993), indicating that there are relationships among four groups of business concepts including business strategy, IS strategy, business infrastructure, and IS internal domain elements. Both business and IS strategies are externally oriented, including business/IS scope, business/IS performance criteria, and business/IS governance. The internal business infrastructure/IS domain elements include the administrative infrastructure and IS architecture, business/IS processes, and business/IS skills. The model has recently been applied to investigate the alignment between business strategy and IS strategy as well as the impact of IS strategy on business and IS performances empirically (e.g., Chan, Huff, Copeland, \& Barclay, 1997; Sabherwal \& Chan, 2001; Sabherwal, Hirschheim, \& Goles, 2001).

These studies explicitly focused on the alignment of two groups of elements in the Strategic Alignment Model (e.g., IS strategy and business strategy, or IS strategy and IS structure) and they undoubtedly generated valuable insights into the impacts of the alignment on business/IS performance. However, it is important to take a more holistic view, as suggested by Henderson and Venkatraman's (1993) four perspectives (strategy execution, technology transformation, competitive potential of technology, and service level alignment), in order to describe relationships among any three of the four groups of business concepts in the strategic alignment model. The three related groups of concepts in the service level perspective are IS strategy, IS internal domain elements, and business infrastructure operations. IS strategy represents the external position of a firm's IS, including technology scope (e.g., imaging technology, LAN and WAN technologies), the required IS performance (e.g., reliable and flexible information services), and the governance structure (i.e., the balance between IS in-sourcing and outsourcing). IS internal domain elements include: (1) IS development, operations, and maintenance processes; (2) IS architecture (such as a portfolio of hardware, software, and communication systems); and (3) skills of IS people. Business infrastructure operations represent various processes, such as new product development, marketing, and accounting. The service level perspective focuses on the proposition that IS strategy can be the driver in designing and implementing IS internal domain elements to support business infrastructure operations.

In the conceptual model in Figure 1, the service level perspective will be followed. The vertical dotted lines with arrows indicate the corresponding relationships between the elements of the conceptual model and those of the service level perspective of the strategic alignment model. The 
solid lines with arrows indicate influential relationships among competences and IS performance. The model is based on the follwoign rationale. First, IS leadership mainly represents the competence of IS management to work with business management to explore how IS should contribute to business performance and thus, set up appropriate IS performance criteria and allocate necessary resources. It is believed that IS leadership competence largely determines the external position of a firm's IS, that is, IS strategy.

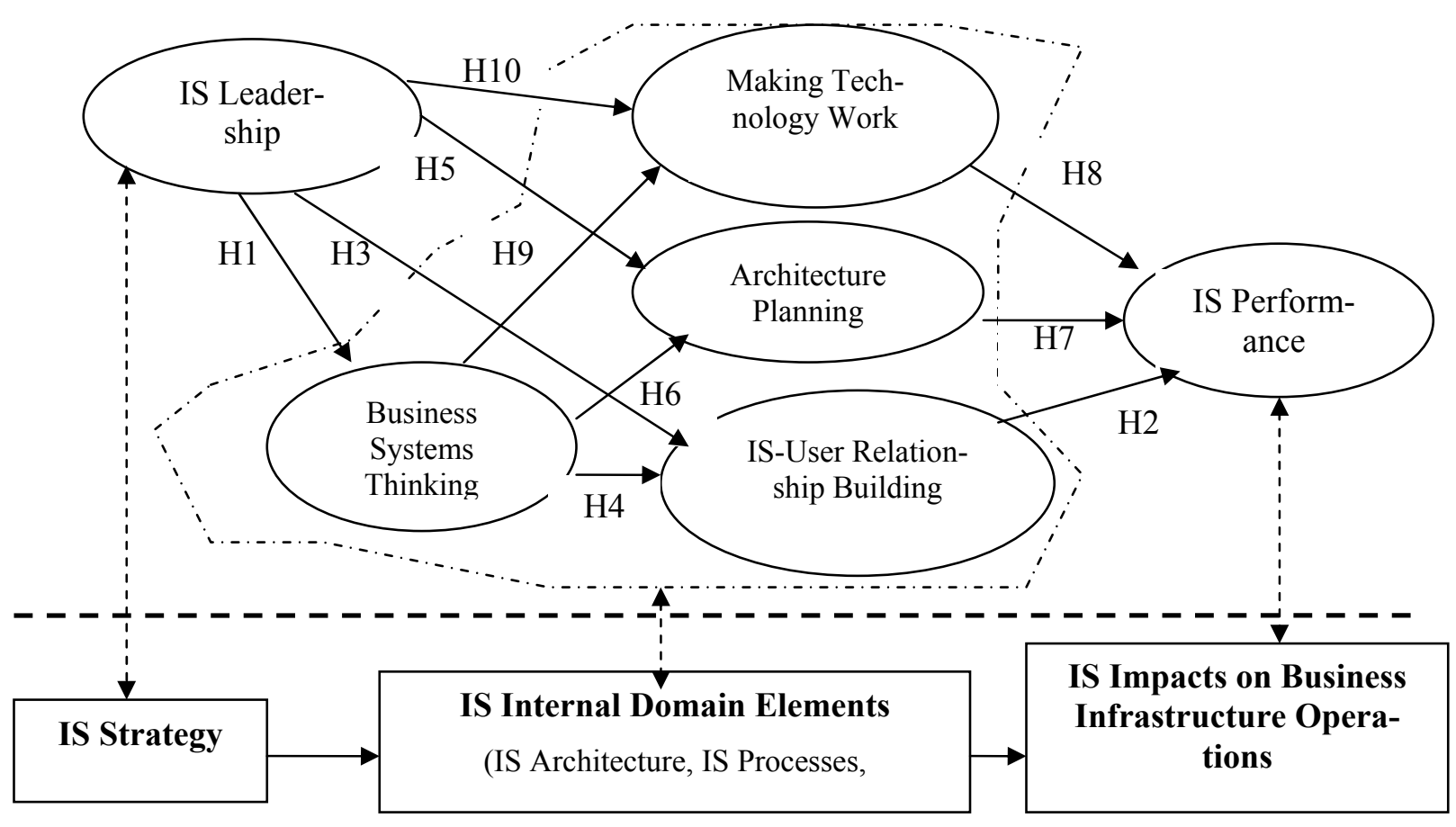

\section{Figure 1: The Conceptual Model and Its Corresponding Relationship with the Service Level Perspective of the Strategic Alignment Model}

Note: The conceptual model is above the horizontal dotted line, while the service level perspective of the Strategic Alignment Model appears below the dotted horizontal line.

Second, the competences of business system thinking, user relationship building, architecture planning, and making technology work, with a focus on IS implementation, can guide the development and define the strength of IS internal domain elements - IS processes, IS architecture, and IS skills. Third, IS performance represents the extent to which IS can enhance business infrastructure operations, such as decision making and cost reduction. Fourth, as indicated by the service level perspective of the alignment model, IS strategy will direct the design and development of IS internal domain elements, which will then impact IS performance. Consequently, if the empirical test of the conceptual model in the paper generates reasonable fit indices and coefficients, then the test provides evidence to confirm the linkages among various IS competences and, naturally, validate partially the service level perspective of the alignment model in Henderson and Venkatraman (1993).

\section{Constructs and Hypotheses}

IS Leadership is the capability of IS executives to integrate IS efforts with business purposes and activities (Feeny \& Willcocks, 1998). Johnston and Carrico (1988) proposed that leadership is both the vision to see the strategic opportunities and the personal force and persistence to over- 
come barriers to effective implementation. Similarly, Earl and Feeny (1994) indicated that the added value from the CIO are: (1) the obsessive and continuous focus on business imperatives and the interpretation of external IT success stories (which are related to seeing the strategic opportunities), and (2) the establishment and maintenance of IS and business executive relationships, the achievement of a shared and challenging vision of the role of IT, and the concentration of the IS development efforts (which are related to personal force and persistence to overcome barriers to effective implementation). Further, Feeny and Willcocks (1998) indicated more comprehensively that effective IS leaders set IS goals and directions, shape the values and culture of the IS function, influence the overall business perception of the role and contribution of IS, instill the belief that IS function's first duty is to contribute to achieving business solutions, devise organizational structures and processes, put capable people at the right place to deal with challenging business issues and manage their interdependencies, and build a strong business-IS relationship. Finally, a recent study on the Web-based business-to-business electronic commerce deployment also found that the lack of top management vision on the potential e-commerce contributions/risks and that of necessary resources are the key reasons why firms are not deploying Bto-B ecommerce systems (Teo, Ranganathan \& Dhaliwal, 2006). In all the above cited studies, there is a strong emphasis on the contributions of IS leadership, i.e., the impacts on business performance of the strategic choices made by top management, who are capable of proactively selecting and establishing their business environments (Child, 1997). It has been proposed above and will be discussed in detail in the following that IS leadership impacts IS performance through driving other IS competences.

Business System Thinking is the capability of IS employees to understand process activities and their inter-relationships. This is the foundational capability for IS function to contribute to business performance. The importance of business system thinking is demonstrated in Teo and King's (1997) finding of the importance of IS mangers' business knowledge, C. P. Armstrong and Sambamurthy's (1999) finding of the impact of CIO's business knowledge and knowing system on IT assimilation, the recognition by Karami, Gupta, \& Somers (1997) and Bassellier and Benbasat (2004) that IT-Business integration is one dimension of IS competence, and in Ross, Beath, and Goodhue's (1996) conceptualization of human resources as the IS personnel's understanding of business systems. A high level of IS leadership can provide the correct vision and allocate necessary resources for IS employees to make full use of their potential in analyzing organizational activities, exploring their interdependencies, and designing an appropriate interactive relationships among these activities. These premises lead to:

Hypothesis 1: A higher level of IS leadership leads to a higher level of the business system thinking competence.

Relationship Building refers to the efforts to motivate business users to become actively and constructively engaged in IS issues and problems. It involves developing users' understanding of the potential of an information system, ensuring users' ownership of and satisfaction with the IS, helping users and IS specialists to work together, and enabling IS personnel to better understand user needs (Feeny \& Willcocks, 1998). Among Teo and King's (1997) ten benchmark variables, there is a user participation element in the IS planning process, which illustrates the importance of relationship building. Feeny and Willcocks (1998) pointed out that relationship building facilitates the wider dialogue between business functions and IS communities. It also contributes to the creation of mutual confidence, the development of harmonious purposes, and successful communications between business and IS people. Rockart, Earl, and Ross (1996) also proposed that "the key people using IT in any organization are its functional, product and geographical line managers and thus their commitment to the IT/IS implementation will ultimately convert the new IS vision into business processes. IT personnel must develop strong, on-going partnerships with line managers". Similarly, Ross and colleagues (1996) treated relationship assets as one important 
element of IS competences. They found that the more IT staff people and clients work together, the more they communicate, coordinate, negotiate, laugh, and cry together, up and down the hierarchy, the stronger the partnership becomes and the more effective are the planning, development of new applications, and use of the current IT.

In addition, Nelson and Cooprider (1996) identified that relationship factors such as mutual trust and influence positively impact IS performance and Henderson (1990) proposed that the partnership between IS and line functions is one critical element in improving IS performance to achieve competitive advantages. Pawlowski and Robey (2004) indicated that IS professional can play the knowledge brokering role among user organizations, and the partnership between IS and line functions is the key institutional environment within which this knowledge brokering activity is accomplished. Consequently, through the mediation of the knowledge brokering process, ISbusiness partnership can improve IS performance for organizational advantages. Recently, Ray, Muhanna, and Beney (2005) also found that tacit, socially complex, and firm specific IT resources, such as IS relationships with user managers, can explain the variation in customer service process performance across firms. Indeed, the growing depth of user satisfaction and technology acceptance studies themselves demonstrate the importance of user relationship building for IS performance; see Venkatesh, Morris, Davis, and Davis (2003) and Wixom and Todd (2005) for recent reviews and research development. This discussion suggests:

Hypothesis 2: A higher level of relationship building efforts will lead to a higher level of IS performance.

To effectively build relationships between IS and line functions, first, top management should set up a clear vision for the potential of IS in driving business performance and allocate necessary resources for IS and other functions to work together to fully exploit that potential (Henderson and Ventraman, 1993). Second, the capability of IS employees to think through the whole business system is imperative and it is the basis to construct a shared knowledge that facilitates partnership building between IS and business functions (Henderson, 1990). Indeed, Bassellier and Benbasat (2004) empirically found significant impacts of both leadership and business system thinking (i.e., IT-Business integration) on IS-user relationship development intentions. This discussion suggests the following hypotheses:

Hypothesis 3: A higher level of IS leadership leads to a higher level of relationship building efforts.

Hypothesis 4: A higher level of business system thinking competence leads to a higher level of relationship building efforts.

Architecture Planning was proposed by Feeny and Willcocks (1998) to mean a capability of IS function to create a coherent blueprint for an administrative and technical platform that responds to both current and future business needs. They indicated that architecture planners should develop a vision for the platform and they should formulate policies to ensure the necessary integration and flexibility of IS services through the platform. This proposition is indeed consistent with Henderson and Venkatraman's (1993) argument in the service level perspective stating that the design of a flexible and integrated IS architecture requires the guidance from IS strategy (i.e., the external position of a firm's IS). Since IS strategy is, to a large degree, developed under the IS leadership of a firm, we propose:

Hypothesis 5: A higher level of IS leadership leads to a higher level of architecture planning competence.

In addition, since the creation of a coherent blueprint, to a large degree, depends on what business activities the platform is supporting and how those activities interact with each other, it is clear 
that good understandings of these activities and their inter-dependencies are required. This analysis leads to:

Hypothesis 6: A higher level of business system thinking competence leads to a higher level of architecture planning competence.

Analyzing case studies, Broadbent and colleagues (1999) found that a better designed IS architecture can enable first mover advantages by facilitating more innovative, radical, and crossfunctional process changes. A recent study by Mitra (2005) also identified evidence demonstrating the contribution of a superior IS infrastructure to the operational cost reduction for high growth firms. In addition, even though architecture planning is sometimes outsourced, IS architecture planning cannot totally become IS suppliers' responsibility. This is because without necessary in-house expertise, a company can not understand the viability of addressing new demands or the potential for meeting existing demands on a new technology platform with better economics (Cohen \& Levinthal, 1990; Earl, 1996; Feeny and Willcocks, 1998; Lacity and Hirschheim, 1993). This evidence suggests:

Hypothesis 7: A higher level of architecture planning capability improves IS performance.

Making Technology Work refers to the capability of IS personnel to rapidly achieve technical progresses (Feeny and Willcocks, 1998). Ross and colleagues (1996) regarded technical skills as one dimension of human assets, and Rockart and colleagues (1996) pointed out that "as companies purchase packages from firms like SSA, SAP, and Baan, IT staff must understand the system and adapt it to the platforms the firm can utilize and troubleshoot code or table-driven procedures that were written outside the firm." Lee and colleagues (1995) clearly indicated the increasing needs for skills and knowledge of technical specialties for IS managers in the future. In addition, Feeny and Willcocks (1998) proposed that in an environment of complex, networked, multisupplier systems, technical "fixers" make two critical contributions: (1) they rapidly troubleshoot problems that do not belong to any other units, and (2) they identify how to address business needs that can not be properly satisfied by standard technical approaches. Teo and colleagues (2006) have also recently found that unresolved technical issues such as encryption, authentication, payment, data and system security, and the lack of robust solutions to prevent denial-ofservice attacks all undoubtedly confuse potential B-to-B e-commerce firms and discourage them to deploy web-based applications for e-commerce. This evidence suggests:

Hypothesis 8: A higher level of making technology work competence leads to a higher level of IS performance.

Further, it is important to realize that in order to make technology work it does not suffice to merely manipulate technologies without a business end in mind. Rather, one has to design codes and functions in order to accomplish business activities. This reasoning leads to:

Hypothesis 9: A higher level of business system thinking competence leads to a higher level of making technology work competence.

Finally, since IS leadership not only establishes a long-term vision motivating IS employees to work hard in anticipating future rewards, but also allocates necessary resources enabling IS employees to do their jobs efficiently in a supportive working environment, the concluding hypothesis is created:

Hypothesis 10: A higher level of IS leadership leads to a higher level of making technology work competence. .

In summary, two points can be made through all the hypotheses development. First, these ten hypotheses provide a detailed elaboration of the linkages in the service level perspective of the Stra- 
tegic Alignment Model in Henderson and Venkatraman (1993). Specifically, IS leadership, to a large degree, determines the IS strategy (i.e., the external position of IS of a firm); the other various competences define the strength of IS internal domain elements including IS processes, skills, and the architecture; and IS performance captures the impact of IS internal domain elements on the efficiency and effectiveness of business infrastructure operations. The linkages from IS strategy through IS internal domain elements to IS performance concretely explain the service level perspective of the alignment model. Second, it is clear that the conceptual model reminds us of the need to face all the information, IT, and organization challenges when coping with IS management issues. The business system thinking competence is mainly about gathering and analyzing process information to help convert the vision from the top management into detailed business knowledge in people's mind and facilitate employees to use IS to redesign and redefine business processes. The making technology work and architecture planning competences are clearly more technology related. And the IS leadership and relationship building competences are related to how to organize and manage people into powerful forces to achieve business objectives.

\section{Methodology}

\section{Measurement}

The scale for measuring IS leadership and business system thinking is based on the work of Johnston and Carrico (1988) and Ross and colleagues (1996). The measurement of relationship building is based on the work of Rockart and colleagues (1996) and Nelson and Cooprider (1996), while the scale for architecture planning is based on the study of Broadbent, Weil, and St. Clair (1999). Ross and colleagues (1996), Rockart and colleagues (1996), Lee and colleagues (1995) and Feeny and Willcocks (1998) provided the basis for measuring the construct of making technology work. The scale for IS performance is based on Venkatraman's (1997) concept of managing IT resources as a value center that consists of cost, service, investment, and profit centers. The IS performance items measure user satisfaction, benefits compared with costs, the creation of business competences through IS in enhancing decision making and business management.

Field interviews were conducted to explore and verify the content domain and test the validity of these items. Two IS directors and one quality director from two auto parts suppliers agreed to be interviewed. There were four interviews in total, and each took between 1-2 hours. The feedbacks received were used to refine and redesign scale items. After interviews, the survey was pre-tested on two dissertation-stage students, two IS professors, and one operation management professor. These methods helped to improve the quality of the survey. Next, a pilot study was conducted.

\section{Pilot Study}

Prior to the administration of a large-scale study, a pilot study was carried out to enhance the reliability and validity of the scales and to further refine the research design. Randomly selected were 500 names from a list containing 3925 IS executives manufacturing and service companies. These companies had to meet at least one of these requirements: (1) IS staff numbers at least $25 \mathrm{em}$ ployees, or (2) over 300 desktop systems are deployed, or (3) being listed on "Fortune 1000," or "Forbes 500," or "InformationWeek 500." Applied Computer Research, Inc. provided this list. Surveys were then administered and phone calls were made to all the 500 potential respondents. There were 31 responses, of which 29 were useful. Corrected item total correlation (CITC) was used to purify the measurement items, and the Cronbach Alpha was used to test the reliability of the scales. Items were deleted iteratively if their CITC scores were below 0.5. The cut-off point for the Cronbach Alpha was 0.70 (Nunnally, 1978). After the pilot study, necessary adjustments 
were made and the quality of the scales was improved. The Appendix lists all the items that were then used in the subsequent main study.

\section{Main Study Methods}

The list with 3425 IS executives' names after the pilot study was used for the main study. Two sets of surveys were administered in the United States, each having several waves with two or three weeks in between. Three hundred phone calls were also made to probe why IS directors and managers did not respond. Similarly to the pilot study, typical reasons were company policy of refraining from surveys, retirements, time constraints, job change, department change, and undeliverable addresses. There were 82 useful responses from the first set of mailing and 123 useful responses from the second set. Altogether, 205 useful responses were received; 198 surveys were returned unanswered due to the reasons mentioned above. The effective response rate is $205 /(3425-198)=6.35 \%$. While this is a low response rate and thus a limitation of this study, the survey generated a dataset that suffices for statistical analysis (e.g., Sethi and King, 1994, used 185 sample points in their structural equation modeling).

Table 1 shows characteristics of the study's sample: $64 \%$ of responding firms are from manufacturing, $17 \%$ from services, $15 \%$ from other industries (transportation and health care), and $4 \%$ of respondents did not specify their industries. As to the size of responding firms, $26 \%$ of them have 1000-2499 employees and 33\% have over 2500 employees. Clearly, big manufacturing firms were most represented in the survey. Around $41 \%$ of the responses are from firms of other sizes. Sales for $82 \%$ of responding firms are larger than $\$ 100$ million, which is consistent with the big percentage of large firms responding. Further, $19 \%$ of the respondents are CIOs, 35\% are IS Directors, $21 \%$ are IS Managers, $11 \%$ are Vice Presidents, while the rest of respondents did not specify their ranks. Thus, with the ranks of all the respondents, it is likely that they are aware of or directly involved in IS management.

Table 1: Characteristics of the Sample

\begin{tabular}{|l|l|l|}
\hline Industry & Frequency & Percent \\
\hline Manufacturing & 131 & 64 \\
\hline Services & 34 & 17 \\
\hline Others (e.g., transportation) & 31 & 15 \\
\hline Unspecified & 9 & 4 \\
\hline Total & $\mathbf{2 0 5}$ & $\mathbf{1 0 0}$ \\
\hline Number of Employees & Frequency & Percent \\
\hline Less Than 100 & 11 & 5 \\
\hline $100-249$ & 12 & 6 \\
\hline $250-499$ & 19 & 9 \\
\hline $500-999$ & 34 & 17 \\
\hline $1000-2499$ & 54 & 26 \\
\hline Over 2500 & 67 & 33 \\
\hline Unspecified & 8 & 4 \\
\hline Total & $\mathbf{2 0 5}$ & $\mathbf{1 0 0}$ \\
\hline
\end{tabular}




\begin{tabular}{|l|l|l|}
\hline Annual Sales (\$) & Frequency & Percent \\
\hline Less than 10 million & 5 & 2 \\
\hline $10-49.9$ million & 9 & 4 \\
\hline $50-99.9$ million & 13 & 6 \\
\hline $100-499.9$ million & 51 & 25 \\
\hline 500 million-1 billion & 48 & 23 \\
\hline Over 1 billion & 69 & 34 \\
\hline Unspecified & 10 & 5 \\
\hline Total & $\mathbf{2 0 5}$ & $\mathbf{1 0 0}$ \\
\hline Respondent Position & Frequency & Percent \\
\hline CIO & 39 & 19 \\
\hline IS Director & 71 & 35 \\
\hline Vice President & 23 & 11 \\
\hline IS Manager & 43 & 21 \\
\hline Unspecified & 22 & 11 \\
\hline Total & $\mathbf{2 0 5}$ & $\mathbf{1 0 0}$ \\
\hline
\end{tabular}

As to non-response bias, two tests of homogeneity were conducted to compare the first set of respondents with the second set of respondents on firm size and sales. The second set of respondents is treated as non-respondents since there is no detailed information about respondents in the original list of names (J. S. Armstrong \& Overton, 1977; Lambert \& Harrington, 1990). It is found that the two Chi-Square values (9.10 for the firm size test and 5.63 for the sales test) are less than the critical value 22.36 ( 0.95 confidence of Chi-Square test with 13 degrees), which means that there are no statistical differences between the first set and the second set of respondents in terms of firm size and sales. Thus, it is concluded that respondent bias does not exist in the data.

Factor analysis was performed for all the constructs in the conceptual model. Varimax rotation was applied and items with lower or cross loadings were deleted and all the factor loadings left were greater than 0.4 with big enough $\mathrm{KMO}$, which verify the necessary discriminant and convergent validity for all derived dimensions. Results are shown in Table 2.

One important finding from the above data analysis is that making technology work competence should be divided into two technology related competences including personal technology competence and IS functional technology competence. While personal technology competence is about each individual's competence in terms of using his/her programming skills and IS knowledge to solve business problems, IS functional technology competence represents the collaborative competence originated from the synergy of all IS people to design technology systems in solving business problems. Consequently, Hypothesis 8, 910 are going to be expanded into H8a, H8b, H9a, H9b, and H10a, H10b as follows:

H8a: A higher level of personal making technology work competence leads to a higher level of IS performance. 
H8b: A higher level of IS functional making technology work competence leads to a higher level of IS performance.

H9a: A higher level of business system thinking competence leads to a higher level of personal making technology work capability.

H9b: A higher level of business system thinking competence leads to a higher level of IS functional making technology work capability.

H10a: A higher level of IS leadership leads to a higher level of personal making technology work capability.

H10b: A higher level of IS leadership leads to a higher level of IS functional making technology work capability.

LISREL was used to test the revised conceptual model. Items were deleted if they have low loadings $(<0.60)$ on their corresponding factors. Item loadings and path coefficients are displayed in the following Figure 2. Fit indices demonstrate a reasonable model fit: Chi-Square $=1088.06$, $\mathrm{df}=421$, Chi-Square $/ \mathrm{df}=2.58, \mathrm{RMSEA}=0.088, \mathrm{RMR}=0.074, \mathrm{NNFI}=0.96$, and $\mathrm{CFI}=0.96$.

Table 2: Factor Analysis

\begin{tabular}{|l|l|l|l|l|l|l|l|}
\hline Items/Factors & 1 & 2 & 3 & 4 & 5 & 6 & 7 \\
\hline LED1 & $\mathbf{0 . 7 3}$ & 0.11 & 0.11 & 0.25 & 0.12 & 0.18 & 0.12 \\
\hline LED2 & $\mathbf{0 . 7 0}$ & 0.05 & 0.11 & 0.31 & 0.12 & 0.21 & 0.06 \\
\hline LED3 & $\mathbf{0 . 6 4}$ & 0.18 & 0.19 & 0.18 & 0.24 & 0.20 & 0.13 \\
\hline LED4 & $\mathbf{0 . 7 3}$ & 0.29 & 0.11 & 0.17 & -0.12 & -0.01 & 0.15 \\
\hline LED5 & $\mathbf{0 . 7 2}$ & 0.35 & 0.18 & 0.13 & 0.00 & -0.06 & 0.18 \\
\hline LED6 & $\mathbf{0 . 6 9}$ & 0.16 & 0.18 & 0.02 & 0.13 & 0.05 & -0.03 \\
\hline LED7 & $\mathbf{0 . 7 1}$ & 0.28 & 0.17 & 0.10 & 0.27 & 0.11 & 0.03 \\
\hline BST4 & 0.14 & 0.21 & 0.14 & 0.11 & 0.20 & 0.14 & $\mathbf{0 . 8 4}$ \\
\hline BST5 & 0.18 & 0.21 & 0.20 & 0.07 & 0.12 & 0.17 & $\mathbf{0 . 8 6}$ \\
\hline ISU1 & 0.24 & $\mathbf{0 . 7 5}$ & 0.09 & 0.02 & 0.15 & 0.12 & 0.04 \\
\hline ISU2 & 0.30 & $\mathbf{0 . 7 1}$ & 0.26 & 0.16 & 0.13 & 0.03 & 0.09 \\
\hline ISU3 & 0.20 & $\mathbf{0 . 7 5}$ & 0.13 & 0.16 & 0.16 & 0.12 & 0.03 \\
\hline ISU4 & 0.12 & $\mathbf{0 . 7 3}$ & 0.22 & 0.14 & 0.12 & 0.11 & 0.19 \\
\hline ISU6 & 0.19 & $\mathbf{0 . 7 2}$ & 0.30 & 0.26 & -0.02 & 0.11 & 0.17 \\
\hline ISU7 & 0.25 & $\mathbf{0 . 6 8}$ & 0.27 & 0.30 & 0.02 & 0.02 & 0.17 \\
\hline ARCH 3 & 0.15 & 0.18 & $\mathbf{0 . 7 3}$ & 0.13 & 0.23 & 0.25 & -0.03 \\
\hline ARCH 4 & 0.13 & 0.13 & $\mathbf{0 . 8 2}$ & 0.11 & 0.24 & 0.19 & 0.07 \\
\hline ARCH 5 & 0.21 & 0.29 & $\mathbf{0 . 8 0}$ & 0.14 & 0.15 & 0.06 & 0.17 \\
\hline
\end{tabular}




\begin{tabular}{|l|l|l|l|l|l|l|l|} 
ARCH 6 & 0.25 & 0.29 & $\mathbf{0 . 7 3}$ & 0.22 & 0.13 & 0.02 & 0.21 \\
\hline ARCH 7 & 0.18 & 0.27 & $\mathbf{0 . 6 8}$ & 0.35 & 0.02 & 0.20 & 0.11 \\
\hline ARCH 8 & 0.21 & 0.22 & $\mathbf{0 . 6 1}$ & 0.38 & -0.03 & 0.19 & 0.13 \\
\hline TECH1 & 0.17 & 0.21 & 0.07 & 0.06 & $\mathbf{0 . 6 5}$ & 0.38 & 0.07 \\
\hline TECH2 & 0.23 & 0.11 & 0.26 & 0.16 & $\mathbf{0 . 7 5}$ & 0.10 & 0.16 \\
\hline TECH3 & 0.09 & 0.11 & 0.19 & 0.12 & $\mathbf{0 . 8 3}$ & 0.07 & 0.13 \\
\hline TECH4 & 0.09 & 0.07 & 0.19 & 0.16 & 0.08 & $\mathbf{0 . 7 2}$ & 0.10 \\
\hline TECH5 & 0.31 & 0.09 & 0.11 & 0.11 & 0.10 & $\mathbf{0 . 7 0}$ & 0.23 \\
\hline TECH6 & 0.03 & 0.15 & 0.22 & 0.12 & 0.20 & $\mathbf{0 . 7 8}$ & 0.00 \\
\hline ISP1 & 0.22 & 0.23 & 0.11 & $\mathbf{0 . 6 2}$ & 0.18 & 0.00 & 0.27 \\
\hline ISP2 & 0.20 & 0.19 & 0.24 & $\mathbf{0 . 7 0}$ & 0.15 & 0.15 & 0.09 \\
\hline ISP3 & -0.12 & 0.01 & -0.23 & $\mathbf{0 . 6 0}$ & 0.11 & -0.10 & 0.00 \\
\hline ISP4 & 0.18 & 0.26 & 0.22 & $\mathbf{0 . 6 9}$ & 0.13 & 0.04 & 0.14 \\
\hline ISP5 & 0.12 & 0.25 & 0.05 & $\mathbf{0 . 7 0}$ & 0.21 & 0.23 & -0.14 \\
\hline Eigen Values & 4.4 & 4.3 & 4.1 & 3.1 & 2.3 & 2.3 & 2.0 \\
\hline Variance Explained & 13.7 & 13.3 & 12.9 & 9.8 & 7.3 & 7.1 & 6.2 \\
\hline Cumulative Variance Explained & 13.7 & 27.0 & 39.9 & 49.7 & 57.0 & 64.1 & 70.3 \\
\hline
\end{tabular}

Note: LED refers to IS leadership; BST refers to business system thinking; ISU refers to IS-User Relationship Building; ARCH refers to architecture building;

TECH refers to making technology work, and ISP refers to IS performance.

\section{Findings}

The first finding, as hypothesized, is that IS leadership improves business system thinking, personal and functional making technology work, architecture planning, and relationship building competences (see Figure 2). Second, it is evident that business system thinking is the second driving force in improving other IS competences including personal and functional technology competences, architecture planning, and relationship building. Third, it is clear that personal technology competence, architecture planning, and relationship building competences positively impact IS performance significantly (at the 0.01 or 0.05 levels). Fourth, it is also evident that while IS functional level technology competence is positively impacting IS performance (i.e., H8b), it is at a lower significance level (0.1) compared with all other hypothesized relationships. 


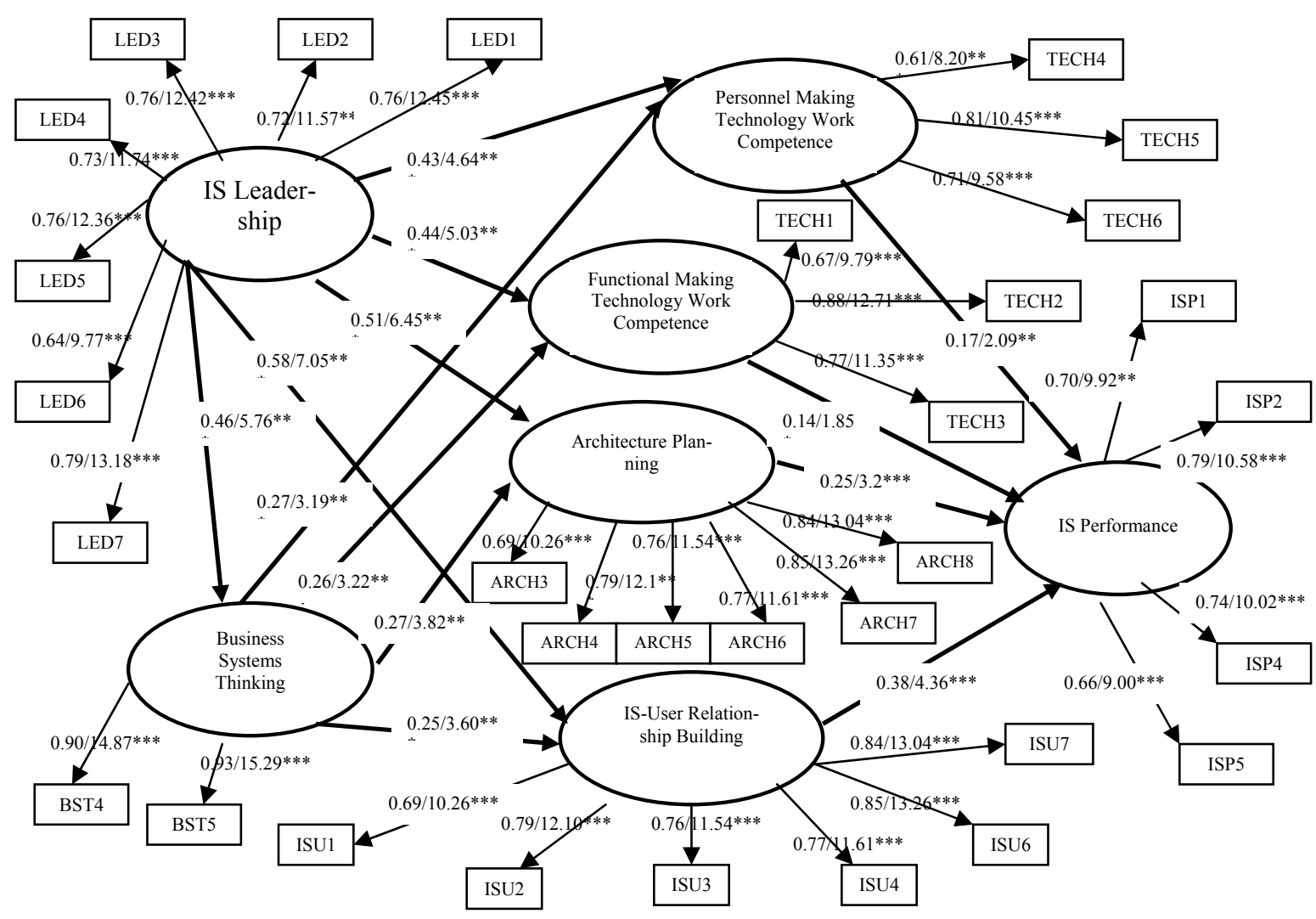

Figure 2: Model Test Results: Scale Items, Factors, Loadings, and Path Coefficients

Note: All paths are significant at 0.01 level; the path from technology competence (functional) to

IS performance is at the 0.1 level $(1.65)^{*}$; the path from technology competence (personnel) to IS performance is at the 0.05 level. $\left(0.05(1.96)^{* *}, 0.01(2.60)^{* * *}\right)$ ). Chi-Square $=1088.06, \mathrm{df}=421$, Chi-Square $/ \mathrm{df}=2.58, \mathrm{RMSEA}=0.088, \mathrm{RMR}=0.074, \mathrm{NNFI}=0.96$, and $\mathrm{CFI}=0.96$

The results of testing the model show reasonable fit indices and all the proposed relationships have significant path coefficients. These significant linkages among IS leadership, IS internal domain elements (represented by various other IS competences), and IS performance partially demonstrate the validity of the service level perspective of the Strategic Alignment Model (Henderson and Venkatraman, 1993). This validation not only helps build up the holistic view of the four groups of business concepts in the alignment model but also provides a solid foundation for practitioners to apply the service level perspective to manage their information systems when it is deemed to be appropriate.

One issue that needs to be discussed more is related to the weakly supported $\mathrm{H} 8 \mathrm{~b}$ (at the 0.1 level), which states that a higher level of IS functional making technology work competence leads to a higher level of IS performance. This weak relationship may imply that in many firms, the synergy among IS people is still missing. It may be very well the case that quite a lot of IS functions do not have the necessary culture, procedures, and systems for effective collaborations in using IS to improve business infrastructure operations. And this explanation is worthy of being empirically investigated more in future studies. 


\section{Conclusion}

The study has several limitations. First, the response rate is low and future research needs to increase this rate to re-confirm findings in the paper. Second, IS outsourcing management competence is not included in the conceptual model. As IS outsourcing is becoming more and more popular, it is necessary to incorporate IS outsourcing management competences into an enhanced conceptual model. Also, it will be interesting to see how both IS outsourcing and IS in-sourcing competences can complement with each other in improving IS performance. Third, IS executives' competence in dealing with a diversity of cultures is not included in the current research. As globalization is becoming necessary for many firms to survive and grow in today's business world, IS executives will have to interact with many cultures, including different languages and country specific customs, when developing and maintaining information systems. (I appreciate an anonymous reviewer reminding me of this.) Naturally, this competence in dealing with different cultures will undoubtedly impact the success or failure of IS development for a global firm and it should be incorporated in future studies. Fourth, while it is appropriate for IS executives to answer survey questions in this study, we have to realize that they may exaggerate IS competences and IS performance. Different perspectives are necessary to provide a more complete and balanced view of a firm's IS competences, IS performance, and their relationships. For example, future studies could collect data from business managers and users and the conceptual model could then be re-tested to verify its robustness.

In conclusion, this study developed a conceptual model, including a comprehensive set of IS competences based on the service level perspective of the Strategic Alignment Model. Among all the competences, IS leadership strongly determines the IS strategy (i.e., the external position of IS of the firm); other competences, such as business system thinking, relationship building, architecture planning, making technology work, define the strength of the IS internal domain elements representing IS processes, skills, and IS architecture; and finally, IS performance describes the impact of IS internal domain elements on business infrastructure operations' effectiveness and efficiency. The interactions among these constructs operationalize the service level perspective of the alignment model.

The empirical test discussed above contributed to IS research by generating additional insights into the relationships among various IS competences. These insights may very well stimulate practitioners to think again about their styles of IS management. Specifically, while the traditional strategy execution perspective (i.e., the movement from business strategy, through business infrastructure, to IS internal domain elements) of the alignment model may be very well understood, this elaborated and validated service level perspective of the alignment model (i.e., from IS strategy, through IS internal domain elements, to business infrastructure operations) certainly enriches our understanding of the model and may very well motivate business/IS executives to think about the possibility of IS as a strong candidate to drive business infrastructure operations for better business performance.

As mentioned earlier, the model development and test can also remind us one more time of the need to take important information, IT, and organizational aspects into consideration when studying IS management. Technology is the tool and information is the content to be processed and utilized. And an organization is the entity to both use technology to process information and consume the produced knowledge for improved business performance. Firms that wish to succeed need to develop all necessary competences (e.g., IS leadership, business system thinking, relationship building, architecture planning, and making technology work) and understand their interactions, such as those specified in the service level and other perspectives of the Strategic Alignment Model to be able to effectively manage information systems. 


\section{References}

Armstrong, C. P. \& Sambamurthy, V. (1999, December). Information technology assimilation in firms: the influence of senior leadership and IT infrastructures. Information Systems Research, 10(4), 304-327.

Armstrong, J. S., \& Overton, T. S. (1977, August). Estimating non-response bias in mail surveys. Journal of Marketing Research, 4, 396-402.

Bassellier, G., \& Benbasat, I. (2004 December). Business competence of information technology professionals: conceptual development and influence on it-business partnerships. MIS Quarterly, 28(4), 673694.

Bharadwaj, A. S. (2000, March). A resource-based perspective on information technology capability and firm performance: an empirical investigation. MIS Quarterly, 24(1), 169-196.

Broadbent, M., Weill, P., \& St. Clair, D. (1999). The implications of information technology infrastructure for business process redesign. MIS Quarterly, 23(2), 159-182.

Boynton, A. C., Zmud, R. W., \& Jacobs, G. C. (1994, September). The influence of IT management practice on IT use in large organizations. MIS Quarterly, 299-318.

Chan, Y. E., Huff, S. L., Copeland, D. G., \& Barclay, D.W. (1997). Business strategy, information systems strategy, and strategic alignment. Information Systems Research, 8(2), 125-150.

Child, J. (1977). Strategic choice in the analysis of action, structure, organizations and environment: Retrospect and prospect. Organization Studies, 18(1), 43-76.

Cohen, W. M. \& Levinthal, D. A. (1990). Absorptive capacity: A new perspective on learning and innovation. Administrative Science Quarterly, 35, 128-152.

Earl, M. J. (1996, Spring). The risks of outsourcing it. Sloan Management Review, 26-32.

Earl, M. J. \& Feeny, D. F. (1994, Spring). Is your CIO adding value? Sloan Management Review, 11- 20.

Feeny, D. F. \& Willcocks, L. P. (1998 Spring). Core IS capabilities for exploiting information technology. Sloan Management Review, 9-21.

Henderson, J, C. (1990, Spring). Plugging into strategic partnerships: the critical IS connection. Sloan Management Review, 31(3), 7-18.

Henderson, J. C. \& Venkatraman, N. (1993). Strategic alignment: Leveraging information technology for transforming organizations. IBM Systems Journal, 32(1), 472-484.

Johnston, H. R. \& Carrico, S. R. (1988, March). Developing capabilities to use information strategically. MIS Quarterly, 37-47.

Karimi, J., Gupta, Y. P. \& Somers, T. M. (1996 Spring). Impact of competitive strategy and information technology maturity on firms' strategic response to globalization. Journal of Management Information Systems, 12(4), 55-88.

Lacity, M. C. \& Hirschheim, R. (1993, Fall). The information systems outsourcing bandwagon. Sloan Management Review, 73-86.

Lambert, D. \& Harrington, T. (1990). Measuring non-response bias in mail surveys. Journal of Business Logistics, 11(2) 5-25.

Lee, D. M. S., Trauth, E. M. \& Farwell, D. (1995 September). Critical skills and knowledge requirements of IS professionals: A joint academic/industry investigation. MIS Quarterly, 313-340.

Mitra, S. (2005, Fall). Information technology as an enabler of growth in firms: an empirical assessment. Journal of Management Information Systems, 22(2), 279-300.

Nelson, K. M. \& Cooprider,J. G. (1996, December). The contribution of shared knowledge to IS group performance. MIS Quarterly, 409-432.

Nunnally, J. C. (1978). Psychometric theory. New York: McGraw Hill. 
Pawlowski, S. D. \& Robey, D. (2004, December). Bridging user organizations: Knowledge brokering and the work of information technology professionals. MIS Quarterly, 28(4), 645-672.

Ray, G., Muhanna, W. A., \& Barney, J. B. (2005, December). Information technology and the performance of the customer service process: A resource-base analysis. MIS Quarterly, 29(4), 625-652.

Rockart, J. E., Earl, M. J., \& Ross, J. W. (1996, Fall). Eight imperatives for the new it organization. Sloan Management Review, 43-55.

Ross, J. W., Beath, C. M., \& Goodhue, D. L. (1996, Fall). Develop long-term competitiveness through it assets. Sloan Management Review, 31-42.

Sabherwal, R. \& Chan, Y. E. (2001, March). Alignment between business and IS strategies: A study of prospectors, analyzers, and defenders. Information Systems Research. 12(1), 11-33.

Sabherwal, R., Hirschheim,R., \& Goles, T. (2001, March-April). The dynamics of alignment: insights from a punctuated equilibrium model. Organization Science, 12(2), 179-197.

Santhanam, R., \& Hartono, E. (2003, March). Issues in linking information technology capability to firm performance. MIS Quarterly, 27(1), 125-153.

Sethi, V., \& King, W. R. (1994). Development of measures to assess the extent to which an information technology application provides competitive advantage. Management Science, 40(12) 1601-1627.

Teo, T. S. H., \& King, W. (1997, Summer). Integration of business planning and information systems planning: An evolutionary-contingency perspective. Journal of Management Information Systems, 14(1), 185-214.

Teo, T. S. H., Ranganathan, C., \& Dhaliwal, J. (2006 August). Key dimensions of inhibitors for the development of web-based business-to-business electronic commerce. IEEE Transactions on Engineering Management, 53(3).

Venkatesh, V., Morris, M. G., Davis, G. B., \& Davis, F. D. (2003, September). User acceptance of information technology: Toward a unified view. MIS Quarterly, 27(3), 425-478.

Venkatraman, N. (1994, Winter). IT-enabled business transformation: From automation to business scope redefinition. Sloan Management Review, 73-87.

Venkatraman, N. (1997, Spring). Beyond outsourcing: Managing it resources as a value center. Sloan Management Review, 38(3), 51-64.

Wixom, B. H., \& Todd, P. A. (2005, March). A theoretical integration of user satisfaction and technology acceptance. Information Systems Research, 16(1), 85-102.

\section{Appendix: Scales}

\begin{tabular}{|l|l|}
\hline LED1 & IS executives actively address business needs. \\
\hline LED2 & IS executives actively manage the inter-dependence among different business needs. \\
\hline LED3 & IS executives assign proper personnel to meet each business function needs. \\
\hline LED4 & IS executives establish business and IS relationships at the executive level. \\
\hline LED5 & IS executives share a vision for IS with business executives. \\
\hline LED6 & IS executives determine the values and culture of the IS function. \\
\hline LED7 & IS executives lead IS staff to contribute to achieving business solutions. \\
\hline
\end{tabular}




\section{Business System Thinking}

\begin{tabular}{|c|c|}
\hline BST1 & $\begin{array}{l}\text { IS function has the capability to integrate business development with IT/IS capability. } \\
\text { (deleted) }\end{array}$ \\
\hline BST2 & $\begin{array}{l}\text { IS function discourages adding new processes without considering current IS/IT capa- } \\
\text { bility. (deleted) }\end{array}$ \\
\hline BST3 & $\begin{array}{l}\text { IS function understands connections and interdependencies among business activities. } \\
\text { (deleted) }\end{array}$ \\
\hline BST4 & IS specialists build holistic views of the current organizational processes and activities \\
\hline BUS5 & $\begin{array}{l}\text { IS specialists communicate holistic views of the current organizational processes and } \\
\text { activities. }\end{array}$ \\
\hline ST6 & on is involved in every significant business initiati \\
\hline
\end{tabular}

\section{Relationship Building}

ISU1 $\quad$ There are efforts to actively develop users' understanding of IS potential.

ISU2 There are efforts to help users and IT specialists work together.

ISU3 There are efforts to ensure users' satisfaction with the various information systems.

ISU4 There are efforts to ensure users' unreserved acceptance of the provided information

\begin{tabular}{l|l} 
ISU4 & systems. \\
\hline ISU5 & Interaction between IS “techies" and "users" is encouraged to reduce any culture gap.
\end{tabular}

ISU5 lnteraction between IS “techies" and "users" is encouraged to reduce any culture gap. ISU6 users.

\begin{tabular}{l|l}
\hline ISU7 & There are efforts to make IS personnel and users perceive a shared purpose.
\end{tabular}

\section{Architecture Planning}

ARCH1 IS function has a well developed vision of an appropriate IS infrastructure for supporting the firm's business. (deleted)

ARCH2 IS function has a well developed vision of an appropriate IS infrastructure for support-

ARCH2 ing its links with suppliers and customers. (deleted)

$\mathrm{ARCH} 3$ IS personnel have designed IS infrastructures to ensure necessary integration of IS serARCH3 vices.

$\mathrm{ARCH} 4$ IS personnel have designed IS infrastructures to ensure necessary flexibility of IS serARCH4 vices.

ARCH5 IS personnel have created a coherent blueprint for IS infrastructure that responds to current business needs.

ARCH6 IS personnel have created a coherent blueprint for IS infrastructure that responds to ARCH6 future business needs.

$\mathrm{ARCH} 7$ IS personnel manage the IS infrastructure to achieve the necessary interrelationships ARCH7 across the business unit's different operations.

ARCH8 IS personnel manage the IS infrastructure to ensure efficiencies across the business unit's different operations. 
IS Functional Making Technology Work Competence

\begin{tabular}{|c|c|}
\hline & \\
\hline & sunction can idenuly innovative soiutions ior non-routme busmess neeas. \\
\hline \multirow[t]{2}{*}{ TECH3 } & $\begin{array}{l}\text { IS function can provide solutions for business needs that cannot be properly satisfied } \\
\text { by standard approach. }\end{array}$ \\
\hline & IS Personal Making Technology Work Competence \\
\hline TECH4 & IS personnel are productive in programming. \\
\hline TECH5 & IS personnel can work in a wide range of technical areas. \\
\hline \multirow[t]{2}{*}{ TECH6 } & $\begin{array}{l}\text { IS personnel have a solid understanding of IT fundamental knowledge to fix IS break- } \\
\text { downs. }\end{array}$ \\
\hline & IS Performance \\
\hline ISP1 & IS is perceived as facilitating organizational decision-making. \\
\hline ISP2 & The user community is generally satisfied with IS. \\
\hline ISP3 & The IS function has not achieved its performance goals. (Reversed Scale, deleted) \\
\hline ISP4 & Use of IS has led to better management of organizational activities. \\
\hline ISP5 & Benefits of IS has outweighed its costs. \\
\hline
\end{tabular}

\section{Biography}

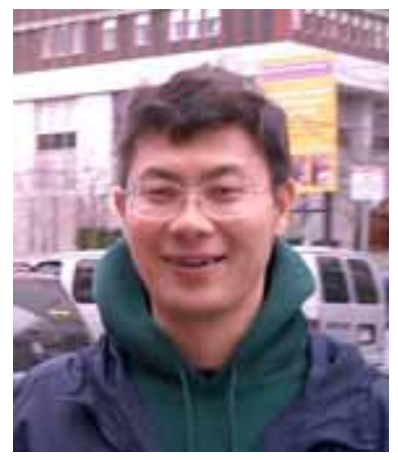

Dr. Zhengzhong Shi is currently an Assistant Professor of Management Information Systems in the Charlton College of Business at the University of Massachusetts Dartmouth. He received his bachelor's degree in Process Control in Chemical Engineering and master's degree in Computer Simulation in Chemical Engineering from Zhejiang University, China. His doctoral degree is from the University of Toledo, USA. He has published in Journal of Intelligent Manufacturing, International Journal of Information Management, Journal of Strategic Information Systems, International Journal of Applied Management and Technology, Information and Management, Journal of Information Technology Impact, and Journal of Information Technology Management. His research interests include information systems strategy, inter-organizational information systems, IS outsourcing, and business-to-business e-commerce. He teaches Information Systems, Database, and Computer Networks classes. 